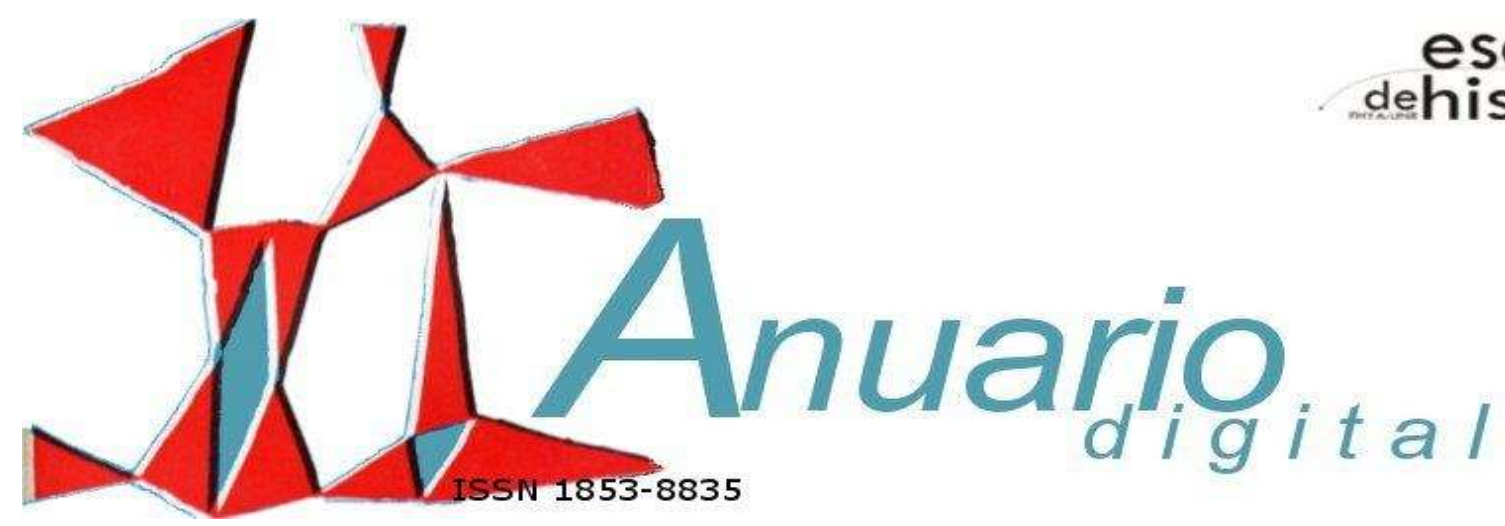

\title{
LA CUESTIÓN DEL PERONISMO EN EL DEBATE ENTRE LAS FAR Y EL PRT-ERP
}

\section{RESUMEN}

El propósito de este trabajo es explorar los principales nudos argumentativos del debate que entablaron en 1971 las Fuerzas Armadas Revolucionarias (FAR) y el Partido Revolucionario de los Trabajadores-Ejército Revolucionario del Pueblo (PRT-ERP). Queremos desmontar el eje de debate que se configura alrededor del peronismo, para estudiar su significado desde el punto de vista de los actores de la polémica. Las fuentes documentales que se revisan en este trabajo son el reportaje a las FAR publicado por la revista Cristianismo y Revolución, la respuesta de un grupo de presos políticos del ERP y los "Aportes al proceso de confrontación de posiciones y polémica pública que abordamos con el E.R.P.". Se analizan las distintas caracterizaciones del peronismo como experiencia popular, movimiento de liberación nacional y alianza de clases (FAR), o como una forma de bonapartismo y nacionalismo burgués (PRT-ERP).

Palabras clave: Peronismo - Bonapartismo - Debate FAR-ERP - Organizaciones armadas

\footnotetext{
* Doctor en Historia por la Universidad de Buenos Aires. Profesor y Licenciado en Historia de la Universidad de Buenos Aires.
} 
The purpose of this paper is to explore the main argumentative knots of the debate between the Revolutionary Armed Forces (FAR) and the Revolutionary Workers Party-People's Revolutionary Army (PRT-ERP). We want to remove the axle of debate that is shaped around the Peronism, to study its meaning from the point of view of the actors in the controversy. The documentary sources reviewed in this paper are the interview to the FAR published in the journal Cristianismo y Revolución, the response of a group of political prisoners of the ERP, and the "Contributions to the confrontation process of positions and public controversy we deal with the ERP". We analyze the different characterizations of Peronism as popular experience, national liberation movement, and class alliance (FAR), or as a form of Bonapartism and bourgeois nationalism (PRT-ERP).

Keywords: Peronism - Bonapartism - debate FAR-ERP - armed organizations

"En la discusión científica, puesto que se supone que el interés es la búsqueda de la verdad y el progreso de la ciencia, resulta más «avanzado» el que se sitúa en el punto de vista de que el adversario puede estar expresando una exigencia que hay que incorporar, aunque sea como momento subordinado, a la construcción propia."

Antonio Gramsci ${ }^{1}$

El propósito de este trabajo es explorar los principales nudos argumentativos del debate entre las Fuerzas Armadas Revolucionarias (FAR) y el Partido Revolucionario de los Trabajadores-Ejército Revolucionario del Pueblo (PRT-ERP), dos organizaciones político-militares que operaron en la Argentina de la década de 1970. La discusión se desarrolló entre abril y noviembre de 1971, y su disparador fue la publicación de un extenso reportaje a las FAR en la revista Cristianismo y Revolución ${ }^{2}$. En la entrevista, el grupo armado liderado por Carlos Olmedo expuso una serie de polémicas digresiones en torno al significado del peronismo, el marxismo, la vanguardia y la lucha armada. La respuesta al controvertido documento no se hizo esperar: entre abril y mayo de 1971, un grupo de presos políticos del ERP dirigido por Domingo Menna que se encontraban recluidos en la Cárcel de Encausados de Córdoba, dio a conocer un breve folleto titulado "Responde el ERP", donde se criticaron varios puntos de la presentación de las FAR. El asesinato de Olmedo en la provincia de Córdoba durante el "Combate de Ferreyra", el 3 de noviembre de 1971, impidió la redacción final de una amplia réplica que el dirigente de las FAR venía preparando. Sin embargo, sus compañeros publicaron el borrador junto a la primera y única respuesta del ERP en un nuevo documento,

\footnotetext{
${ }^{1}$ Gramsci, Antonio; Antología; Siglo XXI; Madrid; 1974; p. 436.

2 "Los de Garín"; Cristianismo y Revolución; № 28 (abril de 1971); pp. 56-70. Disponible en URL: http://eltopoblindado.com/revistacristianismo-y-revolucion/
}

\section{8}

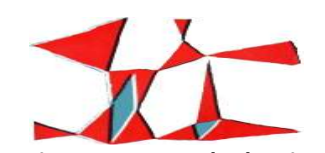

Anuario № 25, Escuela de Historia

Revista Digital № 4, Facultad de Humanidades y Artes, Universidad Nacional de Rosario, 2013 ISSN 1853-8835 
llamado "Aportes al proceso de confrontación de posiciones y polémica pública que abordamos con el E.R.P." (en adelante, “Aportes") ${ }^{3}$. La muerte de Olmedo interrumpió oficialmente el debate, que a pesar de todo continuó en las cárceles que alojaban a los presos políticos de ambos grupos armados, como el penal de Rawson o la cárcel de Villa Devoto.

Creemos que este duelo discursivo es de suma relevancia, ya que sintetizó las diferentes posiciones y coincidencias de las organizaciones peronistas y marxistas en torno al tipo de revolución, el método de la lucha armada, el papel de la teoría y la definición del fenómeno peronista, en una época donde los debates públicos entre las agrupaciones de la "nueva izquierda" brillaban por su ausencia. El aporte puntual de este trabajo consiste en realizar un corte transversal de las FAR y el PRT-ERP, observando el cruce de opiniones y argumentos. Nos interesa evitar los lugares comunes del debate entre la izquierda y el peronismo, ya que preferimos analizar la lógica interna de cada argumento desde una perspectiva crítica, sin caer en la apología ni en la censura de las organizaciones político-militares. El debate entre las FAR y el PRT-ERP es un tema que conserva cierta actualidad, por lo menos en el tenso campo de las relaciones entre el peronismo y la izquierda. Existe una clara línea de continuidad entre el ayer y el hoy de los estereotipos de la izquierda, que reducen el peronismo a una forma de populismo, reformismo o nacionalismo burgués, y también en los clichés del peronismo, cuando se caracteriza a la izquierda como una entidad monolítica separada de las masas, e incapaz de entender al pueblo. Para facilitar el análisis nos parece más útil desmontar los ejes centrales del debate, como el peronismo, la vanguardia, el nacionalismo, el internacionalismo y el marxismo. Nos interesa estudiar el significado de estas categorías desde el punto de vista de los actores históricos, así como rastrear en que constelación ideológica y discursiva se ubican, a que prácticas y lecturas se remiten. En este trabajo, no obstante, vamos a indagar puntualmente el lugar que ocupa el peronismo en el debate. Aunque ésta es una investigación de carácter exploratorio, podemos sugerir a modo de hipótesis que el principal nudo del debate es la "cuestión nacional", tópico que se vuelve central en la época a causa del enorme prestigio de las revoluciones anticoloniales del Tercer Mundo.

\footnotetext{
3 Olmedo, Carlos; “Aportes al proceso de confrontación de posiciones y polémica pública que abordamos con el E.R.P."; en Baschetti, Roberto; Documentos 1970-1973, De la guerrilla peronista al gobierno popular; V. I; De la Campana; Buenos Aires; 2004; pp. 186-214. Disponible en URL: http://eltopoblindado.com/far-documentos/
}

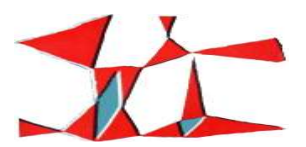

Anuario № 25, Escuela de Historia 
A fines de los sesenta, el régimen militar encabezado por Juan Carlos Onganía empezó a mostrar sus primeros signos de agotamiento, acosado por una ola de protestas que se había extendido rápidamente entre los trabajadores y las capas medias. Si 1969 había sido el año de la espectacular insurrección obrera y estudiantil del Cordobazo, 1970 fue el momento de la guerrilla urbana en la Argentina ${ }^{4}$. El surgimiento de organizaciones político-militares como el PRT-ERP, las FAR, y Montoneros se sumó al accionar de los grupos guerrilleros preexistentes, como las Fuerzas Armadas Peronistas, (FAP), el comando Descamisados y las Fuerzas Argentinas de Liberación (FAL). La multiplicación de las guerrillas urbanas en todo el país acabó con el monopolio de la violencia que detentaba la dictadura militar y contribuyó a erosionar su poder. Las insurrecciones populares, que habían sacudido a las provincias de Corrientes, Córdoba y Rosario entre mayo y septiembre de 1969, mostraron la magnitud del descontento social en proporciones nunca vistas, cuyo emergente mas visible fue el intenso proceso de radicalización obrera y estudiantil. El gobierno de Onganía continuó su marcha a los tropezones, pero terminó de derrumbarse el 29 de mayo de 1970 con el secuestro de Pedro Eugenio Aramburu, protagonista posible de una salida electoral negociada entre bambalinas. Tan solo diez días después de su desaparición, la Junta de Comandantes le pidió la renuncia al jefe de la "Revolución Argentina" y lo reemplazó por Roberto Marcelo Levingston, que en ese momento se encontraba en Estados Unidos como agregado militar. A pesar de la rotación de los vicarios castrenses en el gobierno y la promesa de un cambio con el nombramiento del desarrollista Aldo Ferrer al frente del Ministerio de Economía, la situación política se complicaba cada vez más, conforme aumentaban el accionar de las organizaciones político-militares y crecía el estado de insurgencia civil. En marzo de 1971, Córdoba volvió a ser el epicentro de la protesta contra la dictadura cuando la CGT local declaró una huelga con movilizaciones en contra del nuevo interventor Camilo Uriburu. Este nuevo episodio de lucha en las calles, conocido popularmente como el Viborazo, provocó la renuncia de Levingston y su delegado en Córdoba. El 26 de marzo asumió como presidente el Comandante en Jefe de las Fuerzas Armadas, Alejandro Agustín Lanusse. En ese contexto, la figura de Perón se colocó una vez más en el centro de la escena política, y el rumor de su retorno comenzó a circular con la misma fuerza del mito que se había forjado en los primeros años de la Resistencia, cuando se advertía en voz baja sobre su inminente regreso en un avión negro.

\footnotetext{
${ }^{4}$ Anzorena, Oscar; Tiempo de violencia y utopía: del golpe de Onganía (1966) al golpe de Videla (1976); Colihue; Buenos Aires; 1998; p. 93. En la década de los 60 también se realizaron varias acciones de guerrilla urbana en el país, que no desestabilizaron el escenario político: los últimos comandos de la Resistencia Peronista, las Fuerzas Argentinas de Liberación (FAL), la Guerrilla del Ejército Libertador (GEL) y el Movimiento Nacionalista Revolucionario Tacuara (MNRT).
}

280

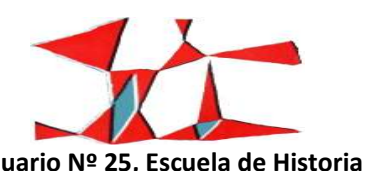




\section{Las FAR y el PRT-ERP, de cara al debate}

Las FAR surgieron de la fusión de varios grupos, como el de Arturo Lewinger y su Tercer Movimiento Histórico, o de disidentes del Partido Comunista Argentino, como Carlos Olmedo, Roberto Quieto y Marcos Osatinsky. En el caso de Arturo Lewinger, el Tercer Movimiento Histórico fue una escisión nacional-popular del Movimiento de Izquierda Revolucionaria-Praxis, organización político-cultural conducida por Silvio Frondizi. Como afirma Guillermo Caviasca, el Tercer Movimiento Histórico apostaba a un "bonapartismo modernizador", en la idea de que un golpe militar nacionalista iba a desencadenar una transformación revolucionaria de la estructura atrasada del capitalismo argentino ${ }^{5}$. Los grupos que venían del Partido Comunista habían protagonizado dos rupturas: la primera fue la de Vanguardia Revolucionaria en 1963, donde militaban Roberto Quieto y Elisa Pastoriza. En cambio, el grupo liderado por Carlos Olmedo, vinculado a la revista La rosa blindada, se separó del Partido Comunista en $1965^{6}$. Otras agrupaciones que se sumaron a las FAR fueron los Comandos Santiago Pampillón, dirigidos por Julio Roqué, algunos militantes de la Democracia Cristiana con presencia en el noroeste de la Argentina y combatientes de la Guerrilla del Ejército Libertador (GEL), provenientes de Santiago del Estero y La Plata. El denominador común en la unificación de todos estos grupos fue la formación de células de apoyo a la guerrilla de Ernesto Guevara en Bolivia, que empezaron a organizarse a fines de 1966. Sin embargo, la propia muerte del Che en Ñancahuazú detuvo abruptamente esta iniciativa y contribuyó a desatar un rápido proceso de "nacionalización" de la guerrilla guevarista, que modificó su perspectiva continental de la lucha armada. El giro hacia lo nacional permitió una nueva apreciación del peronismo como movimiento popular, sin abandonar la teoría del foco en su argumento central: la estrategia de derrotar el ejército burgués mediante una serie progresiva de hechos armados que galvanizaran la movilización de las masas permaneció intacta, pero al desplazarse el teatro de operaciones del campo a la ciudad, también cambió el sujeto revolucionario. La clase obrera se constituyó en el detonante que debía fuminar el foco guerrillero, y el movimiento peronista se convirtió en el vehículo para iniciar un proceso revolucionario de liberación

\footnotetext{
${ }^{5}$ Caviasca, Guillermo; “Arturo Lewinger y los orígenes de las FAR”; en Lucha Armada; № 6; 2006; pp. 82-97.

${ }^{6}$ Las disidencias del PC se producen por varios motivos, entre ellos las críticas internas al rol opositor del partido en el primer peronismo, su posición frente a los procesos de lucha armada en el Tercer Mundo y el apoyo a la Unión Soviética en su enfrentamiento con la China comunista. Otra ruptura importante fue la de los miembros de la revista Pasado y Presente en 1963,0 la separación de un nutrido sector de la Federación Juvenil Comunista, que hacia 1968 fundó el Partido Comunista Revolucionario. V. González Canosa, Mora; "Los pasos previos. Ámbitos disidentes del Partido Comunista y temas de debate en la formación de uno de los grupos fundadores de las FAR"; V Jornadas de Sociología de la UNLP; 2008.
}

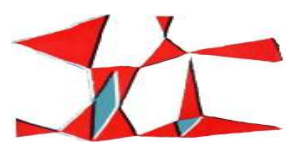

Anuario № 25, Escuela de Historia Revista Digital № 4, Facultad de Humanidades y Artes, Universidad Nacional de Rosario, 2013 ISSN 1853-8835 
nacional, capaz de avanzar hacia una sociedad socialista. De esta manera, las FAR asumieron el peronismo como identidad política sin disimular que sus orígenes se remontaban a la izquierda marxista.

El 26 de junio de 1969, estallaron bombas prolijamente ocultas dentro de pomos de dentífrico en trece supermercados Minimax, una novedad del capital extranjero que estaba arruinando a los almacenes de la pequeña burguesía. El atentado fue realizado para darle la bienvenida a Nelson Rockefeller y fue el primer operativo de envergadura realizado por las "proto-FAR", que no firmaron la acción. Un año más tarde, la organización realizó su primera aparición pública, iniciando una febril actividad que los llevaría a crear regionales en Buenos Aires, La Plata, Tucumán y Córdoba ${ }^{7}$. El 30 de julio de 1970, un comando de la misma organización tomó la localidad de Garín, en la provincia de Buenos Aires, pero en esta ocasión las FAR se dieron a conocer en público a través de un comunicado. La audacia demostrada en esta acción y las operaciones que les sucedieron permitieron que las FAR se ubiquen entre las principales organizaciones político-militares del momento, pero al mismo tiempo llamaron la atención de las fuerzas represivas. El 2 de julio de 1971 dos integrantes de las FAR, Marcelo Verd y Sara Palacios, cayeron secuestrados en la provincia de San Juan y fueron sometidos a tortura, para revelar el paradero de sus compañeros. Once días después, Juan Pablo Maestre y Mirta Misetich fueron raptados por un grupo parapolicial, que dejaría más tarde como único rastro del siniestro el cadáver baleado del primero. Las FAR sufrían así sus primeras bajas, y comenzaban un proceso de acercamiento con varias organizaciones guerrilleras. El 10 de abril de 1972, un operativo conjunto con el ERP acabó con la vida del Teniente General Juan Carlos Sánchez, pero lo más significativo ocurrió el 12 de octubre de 1973, con la declaración formal de la fusión entre las FAR y los Montoneros.

Los inicios del PRT-ERP se remontan al Partido Revolucionario de los Trabajadores, fundado en 1965. Se trataba de una organización política que se formó gracias a la unificación de dos grupos: Palabra Obrera, dirigido por Nahuel Moreno, y el Frente Revolucionario Indoamericanista Popular (FRIP), liderado por Mario Roberto Santucho. Mientras el trotskista Palabra Obrera tenía presencia en los principales

\footnotetext{
${ }^{7}$ González Canosa, Mora; Las Fuerzas Armadas Revolucionarias: orígenes y desarrollo de una particular conjunción entre marxismo, peronismo y lucha armada; Tesis de posgrado defendida en 2012. Presentada en Universidad Nacional de La Plata, Facultad de Humanidades y Ciencias de la Educación para optar al grado de Doctora en Ciencias Sociales; pp. 136-137. Disponible en URL: http://www.memoria.fahce.unlp.edu.ar/tesis/te.808/te.808.pdf. A mediados de 1970 también se dio un debate interno en torno a la inserción en el peronismo, y un acercamiento a las FAP, que incluyó el intercambio de ideas y críticas.
}

282

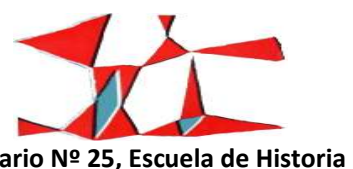


centros urbanos de la Argentina y había cosechado vínculos con la resistencia peronista, el FRIP era una organización más pequeña influenciada por el aprismo peruano y la Revolución cubana, con un trabajo político desarrollado en las universidades y los ingenios azucareros del noroeste. Tras definir su identidad trotskista, en los primeros años de vida del PRT se multiplicaron los debates internos, especialmente en torno a la posibilidad de iniciar un proceso de lucha armada en la Argentina. Los dirigentes otrora ligados a Palabra Obrera sostenían que las condiciones objetivas para tal enfrentamiento no estaban dadas, pero los que tenían un pasado en el FRIP apoyaban con entusiasmo la opción por las armas, afirmando que el partido debía organizar sus propias unidades de combate ${ }^{8}$. En 1968, el PRT se fracturó a causa de estas discusiones y se formaron dos agrupaciones separadas: La verdad, conducida por Nahuel Moreno, y El combatiente, dirigida por Mario Roberto Santucho. En el IV Congreso del PRT, organizado en marzo del mismo año por la fracción proclive a la lucha armada, se criticaron las posiciones "reformistas" de Moreno y se dieron pasos decisivos en dirección a la construcción de una nueva identidad política, como se puede advertir en su documento oficial, El único camino al poder obrero y el socialismo. Allí, Mario Roberto Santucho junto a Oscar Prada y Félix Helio Prieto, dos antiguos cuadros de Palabra Obrera, realizaron una apretada, heterodoxa y ecléctica síntesis política, que trató de combinar los aportes de Marx, Engels, Lenin, el trotskismo, el maoísmo y el castrismo. ${ }^{9}$

En 1969, el PRT El combatiente inició sus primeras acciones armadas, con una serie de pruebas y errores que incluyeron la captura de varios militantes de la organización en Tucumán. Por esta razón, fue recién en el V Congreso del PRT, realizado en julio de 1970, cuando se caracterizó a la situación nacional como una guerra revolucionaria y se creó el Ejército Revolucionario de Pueblo, en medio de una dura lucha de fracciones internas por el poder de la joven organización. A partir del V Congreso, el ERP se organizó como un brazo armado con un programa antiimperialista y popular, a diferencia del PRT, que se reivindicaba socialista y clasista. La relación entre estas dos entidades no siempre fue transparente: aunque la depuración de tendencias concentró el liderazgo en Santucho, formalmente el PRT-ERP se estructuró desde ese momento como un partido marxista de combate, con un buró político y un comité militar. Este

\footnotetext{
${ }^{8}$ Pozzi, Pablo; “Por las sendas argentinas...". EI PRT-ERP. La guerrilla marxista; Imago Mundi; Buenos Aires; 2004 ; pp. $23-24$.

${ }^{9}$ Santucho, Mario Roberto; Escritos [1968-1976]; Último recurso; Rosario; 2006; pp. 15-37. En esta síntesis, empero, no aparece reflejada la gran deuda que ha tenido el PRT-ERP con la tradición revolucionaria vietnamita, a través de los escritos de Vo Nguyen Giap y Ho-Chi-Minh.
}

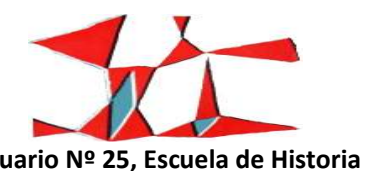


diseño organizativo sirvió para diferenciarlos nítidamente de la típica organización político-militar con comandancia unificada, modelo predominante entre las guerrillas marxistas y peronistas de los 70. Por otro lado, en un principio la gran mayoría de los combatientes del ERP eran al mismo tiempo militantes del PRT, aunque para revistar en los comandos, las escuadras y los pelotones no era requisito indispensable afiliarse al Partido. ${ }^{10}$ Desde 1970, el ERP experimentó un crecimiento sostenido y una fuerte exposición mediática, que no desmereció pero sin duda eclipsó el accionar del PRT en los frentes de masas. En septiembre de 1970, el ERP hizo su primera aparición pública tomando la comisaría 24 de Rosario, enfrentamiento que culmina con dos policías muertos y varios heridos. En la primera mitad de 1971, en vísperas del debate con las FAR, el ERP se destacó como la organización político-militar que más operaciones guerrilleras había realizado en el país, si bien en conjunto los grupos armados peronistas eran los protagonistas de la mayoría de las acciones. Entre marzo y julio de ese año se realizaron 316 operativos, de los cuales 120 fueron firmados por el ERP, 26 por las FAL, 16 por Montoneros, 4 por las FAP y 137 acciones. Casi la mitad fue responsabilidad de organizaciones peronistas o grupos innominados. ${ }^{11}$

\section{El peronismo como experiencia o simulacro}

"El peronismo será revolucionario o no será nada" Eva Perón

En el número 28 de Cristianismo y Revolución, correspondiente a abril de 1971, se publicó un dossier titulado "Reportaje a la guerrilla argentina", con testimonios de las FAR, FAP, Montoneros y FAL. A la cabeza de la sección, se incluyó una entrevista de Paco Urondo a Carlos Olmedo, que debido a razones de seguridad y por tratarse de una declaración oficial de la organización no develaron su identidad ${ }^{12}$. Según el copete que introduce al lector en las circunstancias que rodearon la producción del texto, la serie de reportajes fue publicada originalmente en el diario cubano Granma hacia diciembre de 1970, aunque más tarde "una agencia noticiosa recogió el extenso reportaje que reproducimos en primer lugar", refiriéndose a

\footnotetext{
${ }^{10}$ Pozzi, Pablo; Ob. Cit.; pp. 97-102 y 243-249. Las discusiones del V Congreso entre las tendencias comunista, proletaria y leninista arrojaron como resultado el alejamiento de varios cuadros vinculados a Palabra Obrera, que fundarían el Grupo Obrero Revolucionario (GOR). V. Orero, Eudald Cortina; Grupo Obrero Revolucionario. Autodefensa obrera y guerrilla; El Topo blindado; Buenos Aires; 2011.

${ }^{11}$ Gezé, François y Labrousse, Alain; Argentine. Revolutión et contre-revolutions; citado en Anzorena, Oscar; Ob. Cit.; p. 121.

12 Sobre la autoría del reportaje, v. Duhalde, Eduardo L. y Pérez, Eduardo; De Taco Ralo a la Alternativa Independiente. Historia documental de las "Fuerzas Armadas Peronistas" y del "Peronismo de Base"; De la Campana; Buenos Aires; $2003 ;$ p. 66.
}

284

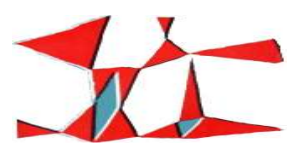

Anuario № 25, Escuela de Historia

Revista Digital № 4, Facultad de Humanidades y Artes, Universidad Nacional de Rosario, 2013 ISSN 1853-8835 
la revista chilena Punto Final. Si bien para Cristianismo y Revolución las FAR "explican allí su acercamiento al peronismo anticipando una futura decisión política al respecto", en esa versión de la entrevista Olmedo no incluye a su organización dentro del movimiento peronista. Sin embargo, cinco meses después, en la entrevista que reproduce Cristianismo y Revolución, aparece una clara identificación con el peronismo. La confusa introducción del reportaje a la guerrilla argentina contribuye a oscurecer estas modificaciones, y hasta el día de hoy en varias investigaciones se repite el error de creer que la entrevista de abril de 1971 es la misma que aquella publicada en el Granma. ${ }^{13}$

El peronismo ocupa un lugar privilegiado en el debate entre las FAR y el PRT-ERP, ya que además de constituir un eje en sí mismo, como ocurre con la ideología, la vanguardia o el marxismo, también participa en todos los temas que toca la polémica. Definir la naturaleza del movimiento peronista constituía un punto relevante en la agenda de las dos organizaciones: la crisis de la llamada Revolución Argentina, y la convocatoria a elecciones realizada por Lanusse habían modificado el escenario político, abriendo la posibilidad del retorno de Juan Domingo Perón a la Argentina. Uno de los elementos más polémicos que aparecieron en el reportaje a las FAR publicado por Cristianismo y Revolución, fue la definición política de la organización, ya que allí se afirmó su expresa intención de formar parte del movimiento peronista:

Nuestra organización se considera expresando lo que podríamos llamar una estrategia de nacionalismo revolucionario. En la Argentina, el nacionalismo revolucionario implica la valoración positiva de una experiencia fundamental de nuestro pueblo, que es la experiencia peronista. Esa valoración positiva por parte de un revolucionario, puede ser entendida tan solo como identificación con esa experiencia, como la asunción plena de esa experiencia. ${ }^{14}$

\footnotetext{
13 Mora González Canosa demuestra que existe una confusión en torno a la entrevista del Granma: "Producto de la confusa introducción de la revista al documento, suele citarse el reportaje a las FAR "Los de Garín" publicado en Cristianismo y Revolución, en donde por primera vez la organización se declara públicamente como peronista, como aquél que habría sido publicado en el diario cubano Gramma en diciembre de 1970. En realidad ese reportaje fue realizado entre febrero y marzo de 1971 siendo publicado inmediatamente en CyR. El reportaje que verdaderamente se publicó en el Gramma fue "FAR: Con el fusil del Che" (op. cit.), en el cual la organización valoriza positivamente el rol del peronismo pero no se incluye como parte del movimiento". V. González Canosa, Mora; "En torno a las Fuerzas Armadas Revolucionarias. Una revisión de la escasa bibliografía sobre el tema y algunas líneas de análisis para su indagación"; XI Jornadas Interescuelas/Departamentos de Historia; Tucumán; 19 al 22 de Septiembre de 2007.

14 “Los de Garín”; Cristianismo y Revolución; №.28; abril de 1971; p. 62. Disponible en URL: http://eltopoblindado.com/revistacristianismo-y-revolucion/
}

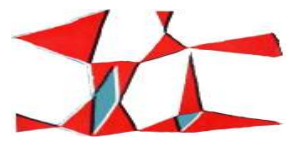

Anuario № 25, Escuela de Historia Revista Digital № 4, Facultad de Humanidades y Artes, Universidad Nacional de Rosario, 2013 ISSN 1853-8835 
En este pasaje se puede advertir como se opera la transición de la perspectiva continental a la local. El nacionalismo revolucionario aparece como un concepto universal, capaz de absorber las particularidades del internacionalismo guevarista y la tradición nacional-popular del peronismo. Por otro lado, la identificación con la experiencia peronista se define como una "asunción plena" y no como una toma de conciencia, aptitud que en el reportaje es exclusiva de los trabajadores. La asunción, en cambio, es un término cuyas connotaciones religiosas (el ascenso a los cielos de la Virgen María) se puede conjeturar varias líneas más adelante:

-Usted me ha hablado, en algún momento de la conversación, de la integración de las FAR al peronismo. ¿Esto quiere decir que la organización no había sido peronista hasta ese momento?

-Su pregunta puede ser equívoca, pero la acepto como tal porque al mismo tiempo es esclarecedora. Nosotros no nos integramos al peronismo; el peronismo no es un club o un partido político al que uno puede afiliarse. El peronismo es fundamentalmente una experiencia de nuestro pueblo y lo que nosotros hacemos ahora es descubrir que siempre habíamos estado integrados a ella, o dicho de otro modo, es desandar el camino de equívocos y malos entendidos por los cuales en alguna etapa de nuestra vida no supimos comprender que siempre habíamos estado integrados a ella en el sentido que está integrado a la experiencia de su pueblo, todo hombre que se identifica con los intereses de los más; y no solo de los más cuantitativamente, sino de aquellos que por su condición, por su ubicación dentro del proceso productivo, son los únicos que pueden gestar una sociedad sin explotación ${ }^{15}$

La explicación de los orígenes no peronistas de las FAR ya se había realizado al comenzar el reportaje, cuando Carlos Olmedo describió los grupos de apoyo a la guerrilla del Che Guevara en Bolivia. Sin embargo, en este pasaje la línea de la argumentación se tensa hacia el problema de la identidad peronista. A diferencia de las FAP, cuya experiencia se remontaba a la época de la resistencia y en marcado contraste con los Montoneros, que eligieron disimular su pasado católico militante, las FAR solo tenían sus credenciales de frustrados soldados del Che a la hora de ingresar al movimiento peronista. Por esta razón, Carlos Olmedo describe la peronización de su organización como el des-cubrimiento del auténtico ser

\footnotetext{
15 "Los de Garín"; Cristianismo y Revolución; №.28; abril de 1971; p. 64. El subrayado en negrita me pertenece.

286

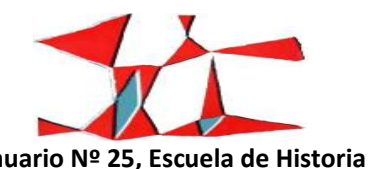

Revista Digital № 4, Facultad de Humanidades y Artes, Universidad Nacional de Rosario, 2013

ISSN 1853-8835
} 
peronista de la organización, antes que en los términos de una conversión, proceso que reforzaría la distinción de las FAR como un extranjero dentro del movimiento peronista ${ }^{16}$. Aquí podemos entender mejor los significados posibles de la "asunción" de la identidad peronista como una auténtica revelación. Como para Olmedo el peronismo es una experiencia del pueblo trabajador, de los explotados y los oprimidos, los militantes de izquierda que crearon las FAR siempre habían sido peronistas, solo que no se habían dado cuenta. ¿Qué pasa entonces con los elementos burgueses, reformistas y burocráticos que cohabitan el movimiento junto a los trabajadores? Paco Urondo sugiere esta relación en términos contradictorios tomando como ejemplo la posición conciliadora de Daniel Paladino, el delegado de Perón, pero la respuesta de Olmedo es contundente:

La contradicción no aparente, sino real, es la que el señor Paladino tiene en realidad, porque si la antinomia peronismo-antiperonismo estuviera superada -cosa que ha sostenido- sería difícil comprender por qué desde el 55 hasta nuestros días se le hace preciso al régimen el escamoteo de las elecciones, el permanente control del poder mediante la violencia organizada y legalizada del Estado, por qué sigue el pueblo proscripto, por qué la oligarquía no admite el retorno de Perón, etc. Esa antinomia no está superada, y sólo podrá superarse con la victoria del pueblo peronista ${ }^{17}$

Para Olmedo, como para John William Cooke, peronismo y antiperonismo no son simples identidades políticas, sino la forma que adopta la lucha de clases en la Argentina, especialmente a partir del golpe de Estado de $1955^{18}$. Por eso, el ser peronista no es "una mera cuestión de nominación", sino la actitud de identificarse con la experiencia popular participando en sus luchas. De nuevo, la dialéctica entre apariencia y esencia habilita la posibilidad de des-cubrir al peronismo, quitándole sus velos reformistas y burocráticos para abrazar su naturaleza revolucionaria.

La difusión del reportaje a las FAR publicado por la revista Cristianismo y Revolución provocó una rápida respuesta del ERP. Entre abril y mayo de 1971, un grupo de presos perretistas encerrados en la Cárcel de

\footnotetext{
${ }^{16}$ La inserción en el peronismo es gradual y conllevó no pocas discusiones. Como observa Mora González Canosa, en el primer reportaje a las FAR, "Con el fusil del Che", el movimiento peronista no se caracteriza como un movimiento de liberación nacional, y la incorporación al mismo aparece como un tema de discusión para la organización. V. González Canosa, Mora; Ob. Cit.; p. 140 y "Con el fusil del Che"; http://www.elhistoriador.com.ar/articulos/los 70/far.php

17 "Los de Garín"; Cristianismo y Revolución; №.28; abril de 1971; p. 64.

${ }^{18}$ Cooke, John William; "Definiciones”; Cristianismo y Revolución; № 2-3; p. 14; octubre-noviembre de 1966. Sobre Cooke, v. Goldar, Ernesto; John William Cooke y el peronismo revolucionario; CEAL; Buenos Aires; 1985.
}

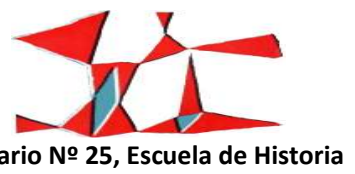


Encausados de Córdoba escribió un breve escrito refutando los conceptos vertidos en "Los de Garín". El principal responsable de este documento fue, según varios testimonios, Domingo Menna, un joven militante nacido en Italia que se integró al PRT en 1965. "El gringo" o "Mingo", como le decían sus compañeros, participó en la fundación de la agrupación estudiantil Espartaco, pero a partir del Cordobazo se desplazó a los frentes fabriles y militares del PRT-ERP. El 12 de enero de 1971 fue detenido por las fuerzas de seguridad en una "casa operativa" de la ciudad de Córdoba junto a el "Pichón" Eduardo Foti, quien recibió un balazo en la cabeza que lo dejó hemipléjico. De la Cárcel de Encausados Menna pasó al penal de Rawson, donde participó junto a varios dirigentes de la guerrilla argentina de la espectacular fuga que lo llevó a Santiago Chile en 1972. Como miembro del Comité Central y Buró Político del PRT, se encargó de la organización del Frente Antiimperialista y por el Socialismo (FAS) y del frente sindical durante el conflicto de Villa Constitución, en 1974. Fue secuestrado el 19 de julio de 1976 por fuerzas del Ejército y permanece desaparecido hasta el día de hoy. ${ }^{19}$ La réplica de Domingo Menna y sus camaradas no fue animada pero tampoco desmentida por la dirección del PRT-ERP, que compartía su mirada sobre el peronismo. No obstante, la contigüidad entre el reportaje a las FAR difundido por Cristianismo y Revolución en abril, el documento redactado por Menna entre abril y mayo y una serie de artículos publicados en $E I$ combatiente entre mayo y julio de 1971, dan cuenta de que para el PRT-ERP el peronismo era un tema que necesitaba ser aclarado ${ }^{20}$. Para empezar el debate, los presos políticos de la Cárcel de Encausados de Córdoba parecen muy preocupados por ordenar las definiciones políticas:

En el reportaje en cuestión definen su estrategia como expresando un nacionalismo revolucionario que implicaría la valoración positiva de la experiencia peronista 'que sería mucho más difícil saber como construir sin el aporte de Marx y Lenin pero que no se construye con el mero aporte de Marx y Lenin sino con el nuestro, con el de la experiencia de nuestro pueblo...', etc. La primera crítica que corresponde es a la utilización de términos en una forma abstracta,

\footnotetext{
${ }^{19}$ Para una semblanza de Domingo Menna, v. Bohoslavsky, Abel; "Biografías y relatos insurgentes"; en Sísifo. La revista del Centro de Estudios Sociales y Sindicales; Año 1, № 1; 2011; pp. 15, 20.

${ }^{20}$ Testimonios de Daniel de Santis y Abel Bohoslavsky, en conversación personal. Los artículos de El combatiente salieron del número 56 al 59, firmados por Julio Parra (Luis Ortolani). V. Remes, Alejo; "El PRT-ERP y su caracterización del peronismo"; ponencia presentada en las XIII Jornadas Interescuelas-Departamentos de Historia; Catamarca; 10, 11, 12 y 13 de agosto de 2011. Disponible en URL:

http://eltopoblindado.com/files/Articulos/09.\%200rganizaciones\%20de\%20origen\%20marxista/Remes,\%20Alejo.\%20\%20El\%20PRT \%20ERP\%20y\%20su\%20caracterizacion\%20del\%20peronismo.pdf
}

288

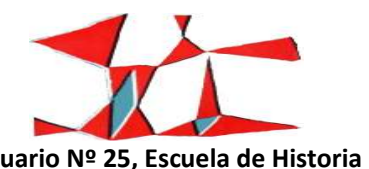

Revista Digital № 4, Facultad de Humanidades y Artes, Universidad Nacional de Rosario, 2013 ISSN 1853-8835 
que impide la definición categórica ante problemas políticos centrales, como es hablar de un nacionalismo revolucionario. Pues esta manoseada palabra sirve al socialismo de Egipto, al socialismo israelí, y también a Barrientos, Ovando y ahora Torres en Bolivia, o, desde Perón, Horacio Sueldo y esa rara mixtura que es 'La hora de los pueblos' en la Argentina. ${ }^{21}$

Esta crítica parece descubrir un "eslabón débil" en la argumentación de las FAR, que se sitúa en el tránsito de lo universal a lo particular, en el hiato abierto entre la estrategia continental del nacionalismo revolucionario y la experiencia peronista. Si para Olmedo la cuestión de la nominación era secundaria, porque de lo que se trataba era de la "asunción" del peronismo entendido como experiencia popular, para Menna las definiciones son el mapa del universo político. Si "el marxismo enseña a los comunistas a luchar también por sus palabras y sus significados", entonces utilizar un vocabulario adecuado es el indicio de la adhesión o la traición al programa de la Revolución socialista, que no se puede reducir al "socialismo nacional” de Perón, Ovando, Torres, etc. ${ }^{22}$ ¿Cuál es entonces la caracterización que hacía el PRT-ERP del peronismo? Un poco más adelante, cuando la polémica gira en torno al problema de la ideología burguesa y la ideología socialista en el ¿Qué hacer? de Lenin, aparece una definición categórica:

No existiendo una tercera ideología porque científicamente no puede responder a ninguna clase, tan sólo puede ser una variante de la burguesa, deformada y deformante, que se viste con ropajes clasistas y revolucionarios cuando en realidad está expresando un populismo como el peronismo en nuestra realidad histórica. Es por eso que se puede ser capitalista como Jorge Antonio y ser peronista, burócrata sindical como Rucci y tantos otros y ser peronista ortodoxo, ser general del ejército y ser peronista ser funcionario de la dictadura y ser peronista, es decir que ser peronista no es obstáculo para mantenerse en cualquier capa o clase social sin ser inconsecuente. ${ }^{23}$

\footnotetext{
21 “Responde el Ejército Revolucionario del Pueblo. Trabajo realizado por un grupo de militantes del ERP, desde la Cárcel de Encausados de Córdoba"; en Militancia Peronista para la Liberación; № 4; 05/07/1973; cfr. Baschetti, Roberto; Ob. Cit.; pp. $179-185$. Disponible en URL: http://eltopoblindado.com/far-documentos/

${ }^{22}$ Esta visión esencialista de las identidades políticas que aparece en el ERP era, paradójicamente, compartida por las FAP, que en un debate interno de 1970: "les replicaban a las FAR que no era lo mismo 'decirse peronista que serlo', aclarando a continuación que ellos 'tomaban al viejo como líder'”, González Canosa, Mora; Ob. Cit.; p. 158. Por lo tanto, si para las FAP se es peronista o no se es (independientemente de una práctica de combate o una identificación ideológica), para el ERP la identidad socialista también es indivisible, ya que se debe aceptar su herencia como un todo. Sobre la idea del socialismo nacional, los intelectuales de la izquierda nacional.

23 “Responde el Ejército Revolucionario del Pueblo..."; en Baschetti, Roberto; Ob. Cit.; p. 181.
}

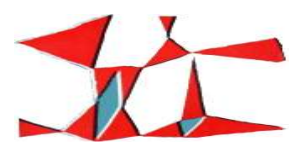

Anuario № 25, Escuela de Historia Revista Digital № 4, Facultad de Humanidades y Artes, Universidad Nacional de Rosario, 2013 ISSN 1853-8835 
Desde el punto de vista del PRT-ERP, el peronismo es un proyecto de desarrollo capitalista autónomo que se cristalizó en una forma de gobierno bonapartista y una ideología nacionalista burguesa. ${ }^{24}$ En la teoría marxista, el bonapartismo es un tipo de régimen político donde el Estado adquiere una relativa autonomía, elevándose en apariencia por encima de las clases sociales para asegurar el predominio de la burguesía, con un discurso cuyas palabras clave son la paz y el orden. ${ }^{25} \mathrm{Si}$ el peronismo era un proyecto nacionalista burgués que quería asegurar la soberanía de las clases poseedoras dentro de los límites de un mercado nacional, entonces la antinomia peronismo-antiperonismo carecía de validez:

El esfuerzo por presentar al peronismo como expresión de la clase obrera corre igual suerte que la pretensión de la vigencia de la antinomia peronismo-antiperonismo. El interés manifiesto expresado desde Lanusse hasta Balbín, pasando por toda la gama de partidos y partiditos de nuestro país, en el regreso de Perón demuestra que tampoco ellos creen en las ideas socializantes de Perón, y que lo conocen mejor que los propios peronistas, lo que sirve para demostrar que la famosa antinomia no existe, lo que existe es una lucha de clases que se da cada vez con mayor intensidad y no es el peronismo el más adecuado para acaudillar a la clase desposeída, desde el momento que se está buscando la vuelta de su líder para que calme los ímpetus revolucionarios de las masas. ${ }^{26}$

En este pasaje queda claro que Domingo Menna no considera a la antinomia peronismoantiperonismo como la forma principal de la lucha de clases en Argentina, tal como creían las FAR apoyándose en las ideas de John William Cooke. Por el contrario, en este argumento el movimiento peronista queda reducido a la figura de Perón, que volvería al país como una alternativa del sistema para poner orden. Dado que para los presos de Córdoba se puede ser capitalista, burócrata sindical, general, funcionario de la dictadura y ser peronista, en el documento de los presos del ERP no parece que "existen

24 Parra, Julio, (Ortolani, Luis); "El peronismo"; El combatiente; № 56; mayo de 1971; p. 7. Disponible en URL: http://eltopoblindado.com/el-combatiente-1971/. Desde ya, esta definición no impedía a Luis Ortolani afirmar en el mismo artículo que: "Existen tantos peronismos como sectores de clases participan o participaron en él"; p. 12.

${ }^{25}$ Demier, Felipe; "Bonapartismo e cesarismo nos estudos sobre o período 1930-1964 da república brasileira: alguns apontamentos introdutórios"; ponencia presentada en ANPUH-XXV Simposio Nacional de Historia; Fortaleza; 2009; pp. 1-2. Disponible en URL: http://anpuh.org/anais/wp-content/uploads/mp/pdf/ANPUH.S25.0019.pdf

26 "Responde el Ejército Revolucionario del Pueblo..."; en Baschetti, Roberto; Ob. Cit.; p. 182-183.

290

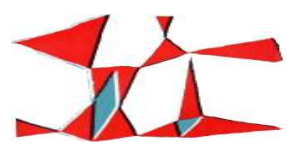

Anuario № 25, Escuela de Historia

Revista Digital № 4, Facultad de Humanidades y Artes, Universidad Nacional de Rosario, 2013 ISSN 1853-8835 
tantos peronismos como sectores de clase participan o participaron en él", según las opiniones vertidas por Luis Ortolani en El combatiente.

\section{Consideraciones finales}

El debate entre las FAR y el PRT-ERP no fue un intercambio en igualdad de condiciones. De un lado se encontraba Carlos Olmedo, un cuadro de notables aptitudes políticas e intelectuales. Olmedo era el hijo de un exiliado político paraguayo y una enfermera. Estudió en el Colegio Nacional Buenos Aires, donde se unió a la Federación Juvenil Comunista, y más tarde debió trabajar como preceptor para financiar sus estudios de Filosofía. Tras su ruptura con el PC, su militancia política daría un giro significativo entre diciembre de 1966 y marzo de 1967, cuando Olmedo viajó a Cuba. En la isla recibió entrenamiento militar, y se comprometió a formar grupos de apoyo al foco boliviano del Che Guevara en Bolivia. Conocido entre los activistas de su organización por diferentes nombres de guerra o apodos como "José", "Germán”, "Rubio" y “El exquisito", habría cursado estudios en La Sorbona y al parecer era muy respetado por Santucho. ${ }^{27}$ Del otro lado se hallaba el grupo de presos políticos liderados por Domingo Menna, un dirigente interesado por la historia del movimiento obrero y por el análisis del peronismo, quienes pudieron elaborar un breve escrito en condiciones durísimas de aislamiento, sin tener acceso a libros ni bibliotecas para fundamentar de manera más adecuada sus posiciones teóricas. ${ }^{28}$ Aunque discutible, es interesante la impresión que tiene Daniel de Santis sobre los diferentes lenguajes del debate:

\footnotetext{
${ }^{27}$ Bonasso, Miguel; El presidente que no fue, Los archivos ocultos del peronismo; Planeta; Buenos Aires; 1997; p. 133. La estadía de Olmedo en Francia también es confirmada por Pedro Cázes Camarero, en conversación personal. Sobre la relación entre Santucho y Olmedo, v. González Canosa, Mora; Ob. Cit.; p. 169. Para una semblanza de Carlos Olmedo, v. Campos, Esteban; “Política armada, violencia y militarización en la guerrilla argentina"; en Navegando por las ciencias, la política y la cultura; ENAH-México; Año III, №4; 2010.

${ }^{28}$ Según Abel Bohoslavsky, con Menna "nos pusimos a estudiar la historia del movimiento obrero argentino y del peronismo en particular. Leímos de todo. Me acuerdo de los artículos de Milcíades Peña en la revista Fichas; de un trabajo de Alejandro Dabat (que era de la dirección del PRT) en la revista Estrategia; del folleto Del anarquismo al peronismo de un sindicalista properonista, Belloni, de muchos capítulos de libros de Rodolfo Puiggrós y del colorado Abelardo Ramos; de un escrito de Jorge Altamira de Política Obrera (Crisis del capitalismo, crisis del peronismo); y muchos escritos de Perón, cartas y discursos (...) Mingo ya había estudiado extensamente el fenómeno del peronismo y, además, la experiencia política de esos años de militancia nos habían convencido que no había perspectiva revolucionaria con esa peronización que ensayaban estos nuevos grupos. La experiencia del "entrismo" hecha por Palabra Obrera la teníamos muy presente. Nos resultaba curioso que muchos compañeros que criticaban a la izquierda y al trotskismo por su inmovilismo, repitiesen el mismo error de los "troskos" que tanto criticaban"; v Bohoslavsky, Abel; Ob. Cit.; pp. 15, 20.
}

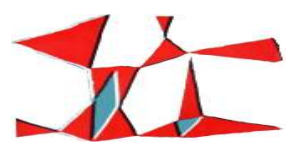

Anuario № 25, Escuela de Historia Revista Digital № 4, Facultad de Humanidades y Artes, Universidad Nacional de Rosario, 2013 ISSN 1853-8835 
Mi impresión es que aparentemente el estudio de Olmedo tiene más solidez, eso, a mi juicio, es porque Olmedo utilizó como base de la polémica La Ideología alemana de Marx y Engels y Menna el Qué hacer de Lenin. Filosofía versus política. ${ }^{29}$

El reportaje a las FAR publicado por Cristianismo y Revolución tuvo dos destinatarios principales: por una parte, los sectores de izquierda más permeables al nacionalismo y la lucha armada, que se intentaba captar a través de una justificación teórica y política de su inserción en el peronismo. Por otra parte, Olmedo trataba de legitimar la nueva identidad de su organización frente al propio movimiento peronista. ${ }^{30}$ En "Los de Garín", el descubrimiento de la "cuestión nacional" implica el pasaje de la estrategia continental del guevarismo a la práctica más localizada del peronismo revolucionario, giro que intentaba evitar el riesgo de volverse "una patrulla perdida en el espacio de la lucha de clases". ${ }^{1}$ La nacionalización de las guerrillas fue una mutación que sufrieron diversos movimientos armados latinoamericanos en la segunda mitad de la década de 1960, tendencia íntimamente ligada a la muerte del Che Guevara en Bolivia y a la derrota de las primeras experiencias de lucha armada inspiradas por el modelo cubano. ${ }^{32}$ Para Carlos Olmedo, el peronismo es una alianza de clases que durante el período 1945-1955, expresó la hegemonía de la burguesía nacional, de allí el discurso justicialista de coexistencia pacífica entre el capital y el trabajo. Sin embargo, la acelerada desnacionalización de la economía argentina y la proscripción del peronismo no solo habían agotado aquella opción, sino que había generado las condiciones para el surgimiento del peronismo revolucionario. De esta manera, para las FAR la antinomia peronismo-antiperonismo reflejaba de manera transparente el antagonismo entre el trabajo y el capital. La inserción en el peronismo es presentada como una asunción, el descubrimiento de una experiencia popular que trasciende la filiación con el movimiento peronista como tal. En este sentido, es sugerente pensar que la identidad peronista no se confunde con los signos formales de la identificación, ni con el apego a determinados nombres y símbolos. Por eso, Carlos Olmedo estaba seguro de que la práctica de su organización no podía compararse con el entrismo de la

\footnotetext{
29 Testimonio de Daniel de Santis, en conversación con el autor (27/08/13). Los subrayados en negrita le pertenecen al testimoniante.

${ }^{30}$ González Canosa, Mora; Ob. Cit.; pp. 168-169.

31 "Los de Garín"; Ob. Cit.; p. 56.

32 Rodríguez Ostria, Gustavo; “Teoponte: la otra guerrilla guevarista en Bolivia”; en Lucha Armada en la Argentina; № 2; $2005 ;$ p. 89.
}

292

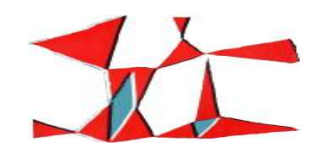

Anuario № 25, Escuela de Historia

Revista Digital № 4, Facultad de Humanidades y Artes, Universidad Nacional de Rosario, 2013 ISSN 1853-8835 
tendencia trotskista morenista, ya que "nosotros no estamos fuera del pueblo, esperando emboscados, sino que pertenecemos a él" ${ }^{33}$

El documento de los presos políticos del PRT-ERP fue una invitación al debate un tanto atípica, ya que su iniciativa no salió del marco de su dirección. A pesar de todo, como sostiene Abel Bohoslavsky, "para debatir, en el PRT no había que pedirle permiso a nadie. La verticalidad tenía vigencia en tareas, sobre todo militares. Y, va de suyo, en la aplicación de las líneas de trabajo previamente adoptadas"34. En su contestación, los militantes del ERP encabezados por Domingo Menna se esforzaron por precisar el significado de conceptos como socialismo y nacionalismo, evidentemente preocupados por la pureza, la clasificación y la segregación de cada identidad política. Desde el punto de vista de la organización dirigida por Mario Roberto Santucho, el peronismo había sido un régimen bonapartista dotado de una ideología nacionalista burguesa, responsable de ensayar un desarrollo capitalista autónomo en la Argentina. Desde este punto de vista, la oposición entre peronismo y antiperonismo era una ilusión alimentada por los políticos burgueses, que solo servía para ocultar la lucha de clases que existía en el país al margen de aquellas identificaciones políticas. En esa misma línea crítica, los presos de la Cárcel de Encausados de Córdoba le dan un peso significativo al papel de los elementos burgueses y burocráticos dentro del movimiento peronista, problema que no se termina de resolver en la serie de preguntas y respuestas entre Paco Urondo y Carlos Olmedo que tocaban el mismo tema. ${ }^{35}$ Para Domingo Menna, el peronismo es reaccionario porque viene a restaurar el deteriorado orden de la dictadura militar. Ni Lanusse, ni Balbín creen en el socialismo de Perón, por eso el enfrentamiento entre peronistas y antiperonistas aparece caracterizado como si fuera un simulacro. Por último, ¿qué implicancias tuvo este debate en el devenir de estas organizaciones? Aunque queda fuera del alcance de nuestra investigación estudiar el complejo fenómeno de la recepción, creemos posible sostener que las intervenciones de Carlos Olmedo contribuyeron a consolidar la propia identidad de la organización, como muestra la reedición del debate por

\footnotetext{
33 "Los de Garín"; Ob. Cit.; p. 65. El "entrismo" fue una estrategia utilizada por las organizaciones trotskistas vinculadas a Nahuel Moreno entre 1953 y 1964 para insertarse en el peronismo y luchar "desde adentro" por la hegemonía del movimiento obrero. Doctrinariamente, se inspiraba en la estrategia de "Frente Único" diseñada por León Trotsky en la década de 1930. V. Castelo, Fernando; “Todos unidos triunfaremos'. El entrismo morenista y sus caracterizaciones"; en Razón y Revolución; no 6; otoño de 2000. Disponible en URL: http://www.razonyrevolucion.org/textos/revryr/luchadeclases/ryr6Castelo.pdf

${ }^{34}$ Testimonio de Abel Bohoslavsky, en conversación con el autor (17/09/13).

${ }^{35}$ Esta idea fue sugerida por Federico Cormick, en el marco del Taller sobre violencia política y lucha armada dictado por El topo blindado hacia el año 2012.
}

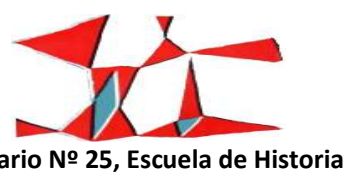


la misma organización tras la muerte de su principal dirigente. En cuanto al PRT-ERP, existen opiniones divididas al respecto: para Daniel de Santis, "nunca se le dio mucha importancia. Los que la han reflotado todo el tiempo han sido los peronistas revolucionarios" ${ }^{36}$. Sin embargo, el historiador Pablo Pozzi, que realizó numerosas entrevistas a ex militantes de la organización, sostiene que hasta la publicación de la nota en Cristianismo y Revolución las FAR eran un aliado estratégico de la organización liderada por Santucho; por lo tanto, el PRT-ERP no solo se habría preocupado por responderle a Olmedo, sino que para Pozzi "el PRT-ERP aceptó la crítica en cuanto a que publicó varios estudios sobre el peronismo que intentaban subsanar el déficit [de formación teórica] sintetizando su posición" ${ }^{37}$ La muerte de Olmedo en el trágico combate de Ferreira hacia 1971, pero quizás también las diferencias cada vez más profundas entre las dos organizaciones a causa del inminente regreso de Perón, impidieron la continuación del debate.

Recibido: 24 de septiembre de 2013

Aprobado: 6 de diciembre de 2013

Versión final: 20 de diciembre de 2013

\footnotetext{
${ }^{36}$ Testimonio de Daniel de Santis, en conversación con el autor (27/08/13).

${ }^{37}$ Pozzi, Pablo; Ob. Cit.; pp. 107-108.

294

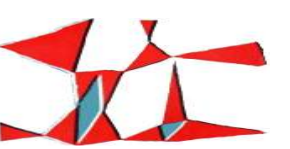

Anuario № 25, Escuela de Historia

Revista Digital № 4, Facultad de Humanidades y Artes, Universidad Nacional de Rosario, 2013

ISSN 1853-8835
} 